\title{
Copepod diversity in the water masses of the southern East China Sea north of Taiwan
}

\author{
Chang-tai Shih ${ }^{\mathrm{a}, \mathrm{b}, *}$, Tai-Sheng Chiu ${ }^{\mathrm{b}}$ \\ ${ }^{a}$ Research Division, Canadian Museum of Nature, Ottawa, K1P 6P4, Canada \\ ${ }^{\mathrm{b}}$ Department of Zoology, National Taiwan University, Taipei 106, Taiwan
}

Revised 22 May 1997; accepted 26 September 1997

\begin{abstract}
The warm oceanic current Kuroshio and the continental shelf water of the East China Sea meet in the western North Pacific, north of Taiwan and form an upwelling when they converge. The intrusion of the Kuroshio westward over the East China Sea shelf thus results in complicated exchanges of waters between these two water masses. We studied the copepods in the plankton collection taken from an east-west transect crossing these waters in April 1995 when the intrusion of the Kuroshio over the East China Sea shelf was beginning to retreat. The taxonomy of copepods was carefully treated and erroneous species records reported in the literature were guarded against. We evaluated the copepod diversity, the association of copepod species, and the association of stations in these water masses. (C) 1998 Elsevier Science B.V. All rights reserved.
\end{abstract}

Keywords: water masses; zooplankton; Copepoda; East China Sea; Kuroshio; species association

\section{Introduction}

The present study is a part of the interdisciplinary research (KEEP-II) on the oceanographic exchange processes between the Kuroshio and the East China Sea shelf water. The KEEP-II study area is boxed approximately by the coordinates $26^{\circ} 10^{\prime} \mathrm{N} 121^{\circ} 50^{\prime} \mathrm{E}$, $24^{\circ} 50^{\prime} \mathrm{N} 123^{\circ} 10^{\prime} \mathrm{E}, 25^{\circ} 50^{\prime} \mathrm{N} 121^{\circ} 30^{\prime} \mathrm{E}$, and $24^{\circ} 40^{\prime} \mathrm{N}$ $122^{\circ} 40^{\prime} \mathrm{E}$.

The Kuroshio, a North Pacific warm current, originates from the North Equatorial Current east of the

\footnotetext{
* Corresponding author. Present address: Institute of Oceanography, National Taiwan University, Taipei, Taiwan 106. Fax: + 886 (2) 363-6837. E-mail: ctshih@ccms.ntu.edu.tw
}

Philippines and flows northward along the east coast of Taiwan. Northeast of Taiwan, it approaches a sharply curved break at the boundary of the East China Sea shelf where a year-round upwelling is formed before the Kuroshio runs northeastward along the shelf edge (Chern et al., 1990; Liu et al., 1992). The location of the upwelling varies, dependent on the degree of the Kuroshio intrusion onto the East China Sea shelf (Chern and Wang, 1989). The waters of the Kuroshio (KUR) and East China Sea (ECS) exchange and mix (MIX, the upwelling) vertically in the KEEP-II study area (Chern et al., 1990).

Some reports on the biological oceanography of the KEEP-II area, including ichthyoplankton (Chiu, 1991; Chiu and Hsyu, 1994), biomass and biochemi- 
cal composition of zooplankton (Chen and Chen, 1992), phytoplankton (Chen, 1995), and primary productivity (Shiah et al., 1995), have been published lately. The taxonomy of copepods is, however, relatively unknown despite the dominance of these animals in zooplankton, both by species diversity and numerical abundance. Tan (1967) reported 42 copepod species from his northern stations near our transect. Tseng (1972) studied Candaciidae taken from north of Taiwan, superimposing with our stations. A list of the copepods collected from the Kuroshio downstream of our sampling sites was given by He and Yang (1990).

Our objectives were to examine the copepod species diversity in the study area, to evaluate the species association among the copepods, and to correlate the copepod distribution with the areal water masses.

\section{Material and methods}

Our samples were collected from eight stations on a transect extending from $25^{\circ} 10^{\prime} \mathrm{N}$ and $122^{\circ} 51^{\prime} \mathrm{E}$ to $26^{\circ} 18^{\prime} \mathrm{N}$ and $120^{\circ} 29^{\prime} \mathrm{E}$ during cruise 416 in April 1995 on board the Ocean Research I (Fig. 1). This transect passed through the water masses KUR, MIX, ECS, and the coastal water of the East China Sea

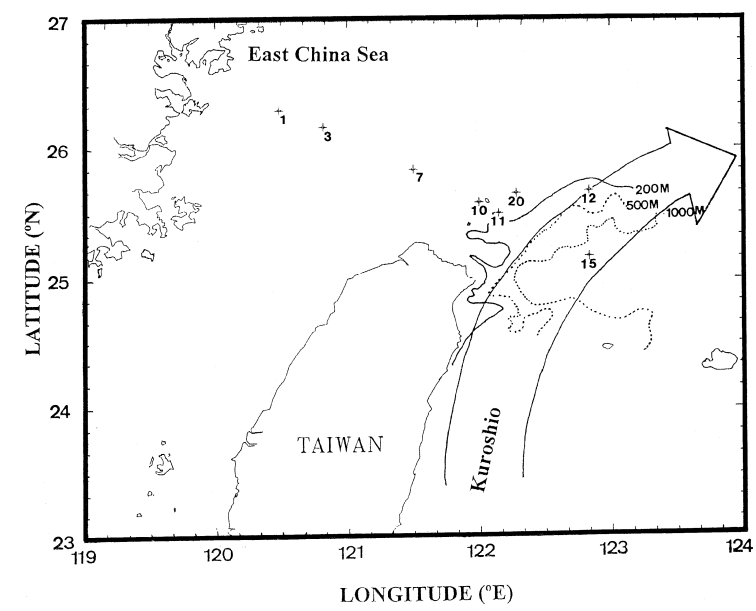

Fig. 1. Localities of stations of Ocean Research I cruise 416 in April 1995 with depth contours of 200, 500, and $1000 \mathrm{~m}$.
(COAST), and crossed various depths from the Okinawa Trough $(>1000 \mathrm{~m})$ to the continental slope $(200-1000 \mathrm{~m})$ to the East China Sea shelf $(<200$ $\mathrm{m})$.

We collected the samples with a Bongo plankton net of $60 \mathrm{~cm}$ mouth diameter and $500 \mu \mathrm{m}$ mesh. A flowmeter was mounted at the centre of the mouth opening. The net was towed obliquely from near the bottom to the surface if the bottom depth was $200 \mathrm{~m}$ or less, and from $200 \mathrm{~m}$ to the surface if the depth was more than $200 \mathrm{~m}$. The samples were preserved in seawater with $5 \%$ formalin. At each station prior to plankton tow, temperature and salinity as functions of depth were obtained from lowering a SeaBird conductivity-temperature-depth (CTD) instrument from surface to near bottom.

In the laboratory, each sample was split by a Folsom splitter until the subsample contained 300500 specimens. Copepods were sorted and identified to species. The number, sex, and copepodite stage of the specimens of each species in the sample were recorded. General references for identification were Chen and Zhang (1965) and Chen et al. (1974), but original and revisional references were consulted.

We used the Shannon diversity index to check the species diversity and Simpson's evenness to measure the relative abundance of species in each station, and in stations of a water mass. The species association of the twenty most abundant species was measured by normalized Euclidean distances. The Spearman rank correlation coefficient between the stations with the UPGMA method was used to illustrate station association. All of the above statistical analyses followed Rholf (1989). We selected the species (hereafter the selected species) which accounted for $1 \%$ or more of the total number of specimens in at least one station to calculate the Shannon diversity index, Simpson's evenness and Spearman's rank correlation coefficients.

\section{Results}

\subsection{Water masses}

The temperature-salinity curves of the stations are shown in Fig. 2 and four types of waters are 


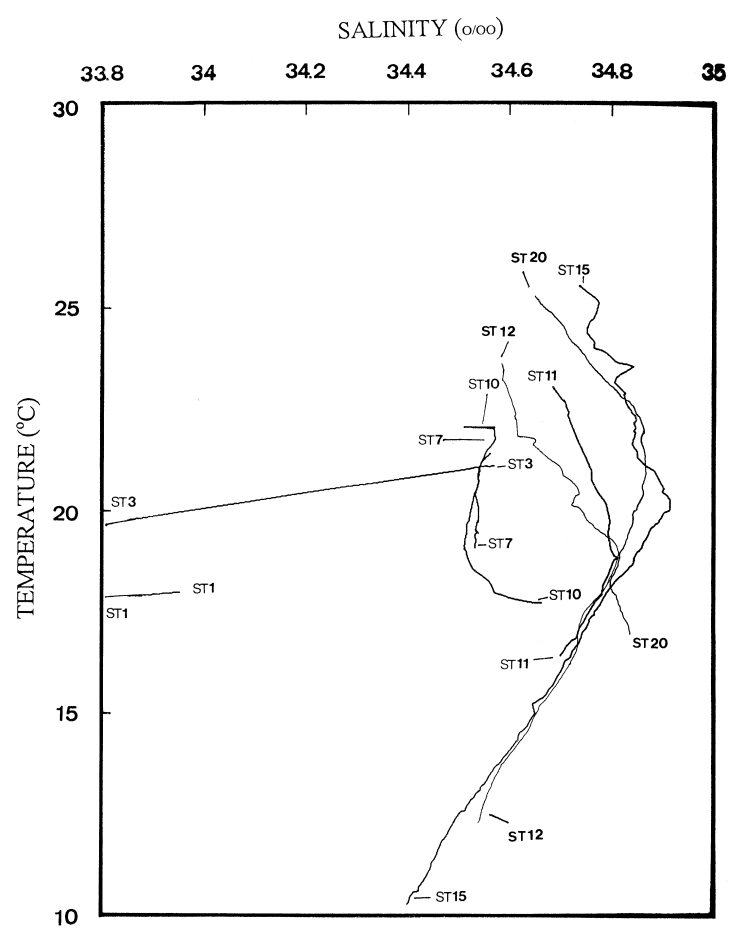

Fig. 2. The temperature-salinity curves of cruise 416 stations showing four different types of water masses.

readily recognized. Stations 1 and 3 have low temperature and salinity, typically of the COAST. Stations 7 and 10 are the ECS characterized by moderate temperature and salinity. Stations 15 and 20 belong to the KUR marked by high temperature and salinity. Stations 11 and 12 exhibit temperatures and salinity intermediate between the KUR and ECS, signifying the MIX

\subsection{Systematics and species diversity}

We found from the samples 113 species of copepods belonging to 43 genera and 22 families: 79 species of Calanoida, 5 species of Cyclopoida, 1 species of Harpacticoida, and 28 species of Poecilostomatoida. Calanus sinicus, Paracalanus aculeatus, Temora discaudata, and Oncaea venusta occurred in all stations. 33 species were found only once, including eight of the ten species of Scolecithricidae. Number of the selected species (boldfaced species in Table 1) and Shannon diversity index varied from 16 and 1.3904 in station 1 to 36 and 3.1315 in station 20. When the stations were lumped according to the water masses where they were located, the Shannon diversity index and Simpson's evenness increased eastward from the COAST to ECS, MIX and KUR (Shannon diversity index: 2.2502, 2.6668, 2.8752, and 3.2750; Simpson's evenness: $0.6375,0.7513,0.8332$, and 0.9504).

\subsection{Species association}

The species association of the twenty most abundant species was measured by normalized Euclidean distances. A dendrogram showing the species association is illustrated in Fig. 3. Species with similar horizontal distribution formed a cluster or close clusters. For instance, Oncaea venusta and Temora discaudata form a cluster, to which Calanus sinicus is joined. These three species are common to all water masses. Several species, absent from or rare in the COAST and/or ECS but relatively common and abundant in MIX and KUR, e.g., Oithona setigera, Pleuromamma gracilis, Lucicutia flavicornis, Corycaeus (Agetus) flaccus, and Clausocalanus lividus, are joined to close clusters at the bottom of the dendrogram.

\subsection{Station association}

Stations 1 and 15 are at the two ends of the dendrogram (Fig. 4) indicating most dissimilar copepod compositions between these two stations. It is apparent that in general the farther the stations are located from each other, the larger the distance is between them in this dendrogram, being a strong reflection of the association between the copepod faunas and water masses.

\section{Discussion}

Results of the biological studies in the KEEP-II program have shown a correlation between the biotic abundance and the water masses. Chiu (1991) and Chiu and Hsyu (1994) found that the abundance of 
Table 1

Copepod species, $\%$ of the total number of specimens in the station, and other collection data

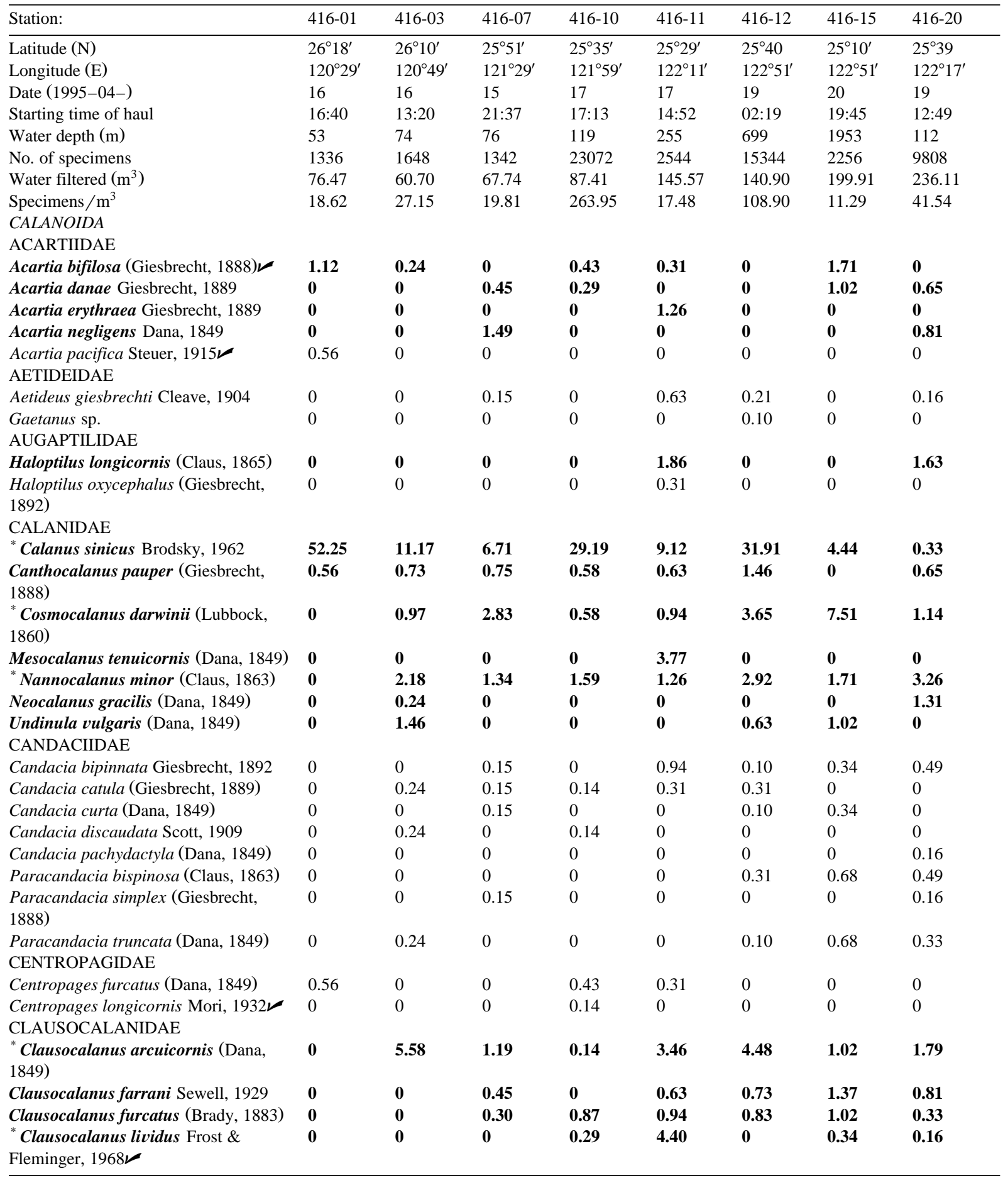


Table 1 (continued)

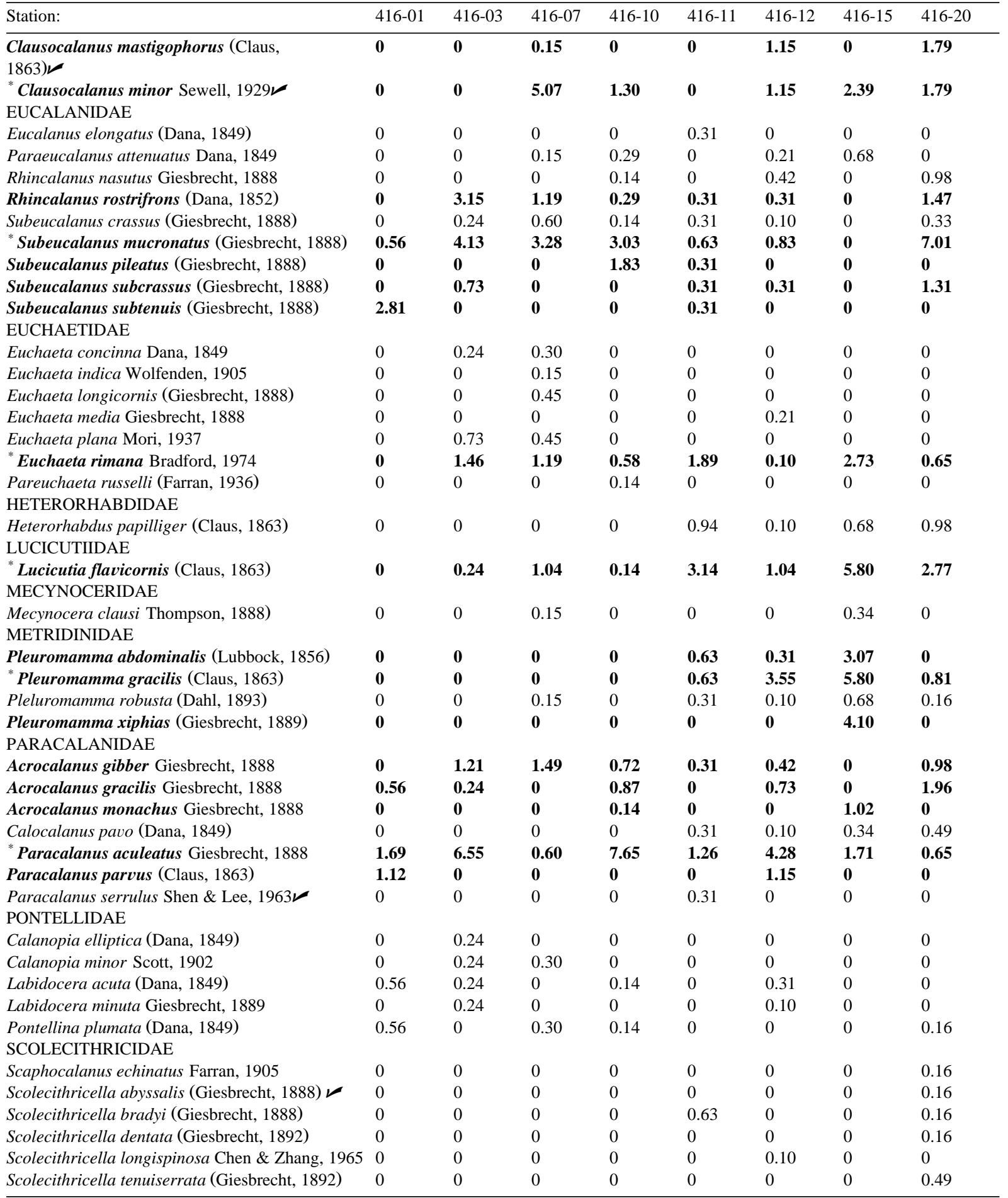


Table 1 (continued)

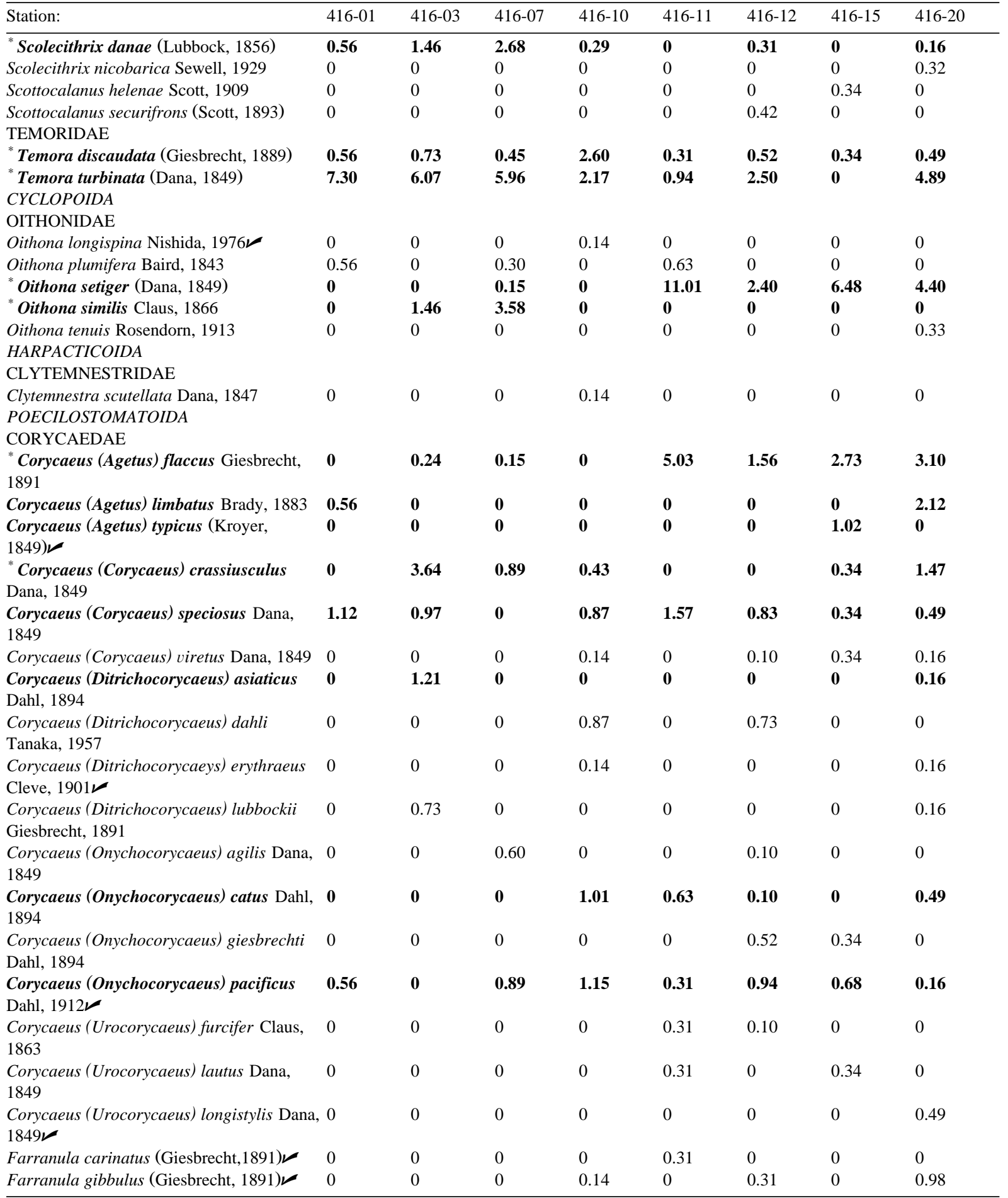


Table 1 (continued)

\begin{tabular}{|c|c|c|c|c|c|c|c|c|}
\hline Station: & $416-01$ & $416-03$ & $416-07$ & $416-10$ & $416-11$ & $416-12$ & $416-15$ & $416-20$ \\
\hline \multicolumn{9}{|l|}{ ONCAEIDAE } \\
\hline Lubbockia squillimana Giesbrecht, 1891 & 0 & 0 & 0.15 & 0 & 0 & 0 & 0 & 0.16 \\
\hline Oncaea conifera Giesbrecht, 1891 & 0 & 0 & 0 & 0 & 0 & 0 & 0.34 & 0 \\
\hline *Oncaea venusta Philippi, 1843 & 6.74 & 8.98 & 3.73 & 11.40 & 4.72 & 2.09 & 5.80 & 8.65 \\
\hline \multicolumn{9}{|l|}{ SAPPHRINIDAE } \\
\hline Sapphirina metallina Dana, 1849 & 0 & 0 & 0 & 0 & 0 & 0 & 0 & 0.16 \\
\hline Sapphirina nigromaculata Claus, 1863 & 0 & 0 & 0 & 0 & 0 & 0 & 0 & 0.16 \\
\hline Sapphirina opalina Dana, 1849 & 0 & 0 & 0 & 0.14 & 0 & 0 & 0 & 0 \\
\hline Total number of species & 21 & 37 & 46 & 44 & 49 & 56 & 41 & 64 \\
\hline Number of selected species & 16 & 26 & 27 & 27 & 32 & 31 & 27 & 36 \\
\hline Shannon diversity index & 1.3904 & 2.7661 & 2.8863 & 2.1191 & 2.9894 & 2.4354 & 2.9523 & 3.1315 \\
\hline
\end{tabular}

Species in boldface: the selected species, i.e., species with $1 \%$ or more of the total number of specimens in one or more stations. Species with asterisk: one of the twenty most abundant species in the whole collection.

Species followed by a tick $(\boldsymbol{})$ : new records for the study area.

fish eggs, larval fishes, and zooplankton was higher in the midshelf stations (ECS) than in the upwelling (MIX) or oceanic stations (KUR). Shiah et al. (1995) observed that the normalized productivity measured by the ${ }^{14} \mathrm{C}$ assimilation method was higher in the
MIX than in the COAST and KUR. Similarly Chen (1995) recorded high primary productivity in the MIX and low primary productivity in the KUR. Chen and Chen (1992) reported that zooplankton biomass was positively correlated with upwelling

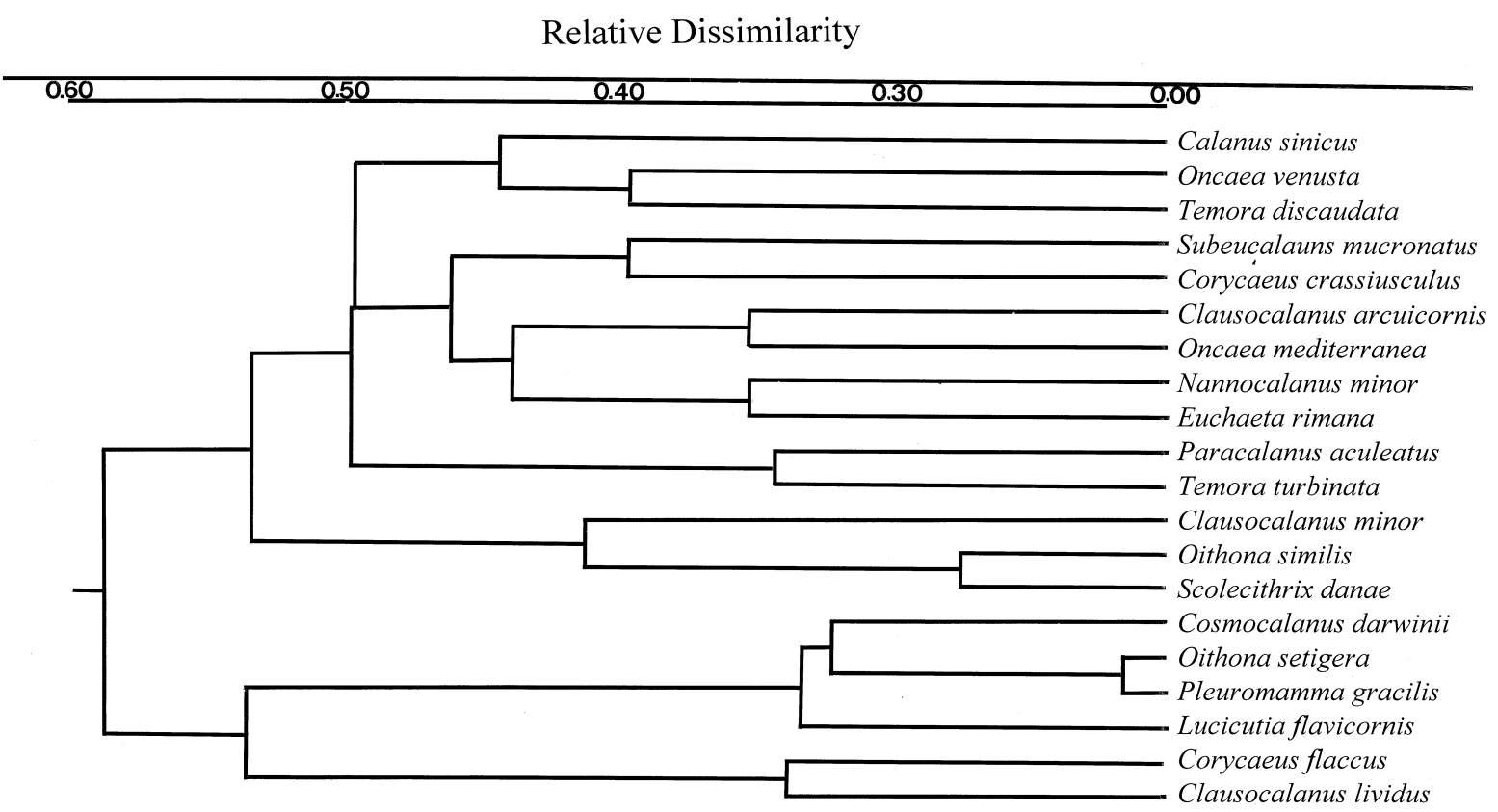

Fig. 3. Dendrogram of the twenty most abundant species measured by Euclidean distances showing the degree of relative dissimilarity of distribution between species in the water masses of the KEEP-II study area. 
Relative Similarity

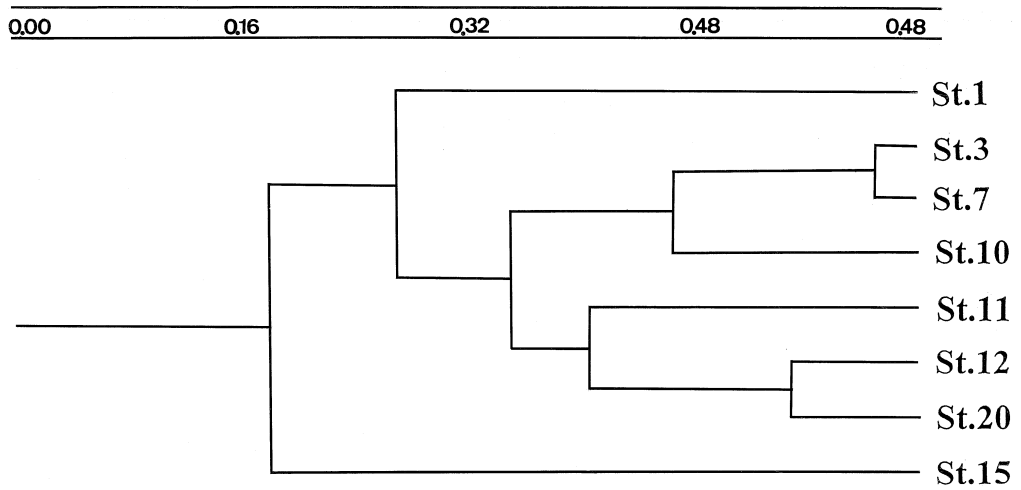

Fig. 4. Dendrogram of station associations calculated from Spearman's rank correlation coefficients showing the degree of similarity in copepod faunas between stations.

indicators such as low temperature and high $\mathrm{NO}_{3}-\mathrm{N}$ and chlorophyll $a$. In our collection, the copepod density (number of individuals $/ \mathrm{m}^{3}$ ) in the four water masses showed a decreasing order from ECS to MIX, COAST and KUR. The present study thus confirms that the biotic abundance is generally higher in the ECS and MIX and lower in the COAST and KUR.

The present work has expanded our knowledge on the copepods of the KEEP-II study area. Some species reported by Tan (1967), for instance, Calanus finmarchicus and C. helgolandicus (North Atlantic species, see Shih, 1979), and Pseudocalanus gracilis and P. minutus (boreal or temperate species, see Frost, 1989), are erroneous records. The two Calanus species probably are misidentifications of $C$. sinicus, and the Pseudocalanus species may belong to some species of the genus Clausocalanus. Candacia pacifica and $C$. pectinata in Tseng (1972) are respectively synonyms of $C$. columbiae and $C$. armata (see Grice, 1963). Fifteen species in our collection, mostly from the KUR and MIX, are new to the study area (marked with a tick in Table 1).

Calanus sinicus is limited to the western marginal seas of the North Pacific, and dominant in the Yellow and East China seas. Its southern distribution limit extends to the South China Sea, especially in winter when the northeast monsoon prevails (Chen, 1992). C. sinicus is the most dominant copepod in our collection except in stations 15 and 20. In con- trast to the large number of adult females and males and numerous younger copepodids present in the COAST, ECS and MIX stations, there were only small numbers of adult females and no (station 20) or very few (station 15) young copepodids found in the KUR stations. The occurrence of this species in the Kuroshio is probably expatriate. C. sinicus usually inhabits the water over the continental shelf but enters the coastal water from April to June (Chen, 1992). Its great abundance in our station 1 confirms Chen's observation.

Euchaeta marina is widely distributed including a number of records from the western North Pacific (Mori, 1937; Chen and Zhang, 1965). Bradford (1974) established and described Euchaeta rimana. She included many previous Pacific records of $E$. marina (including Mori's) under this name. She suggested that E. marina is limited to the Atlantic Ocean and Mediterranean Sea. Our specimens conform with E. rimana in morphology.

We compared the abundance and diversity of the copepods in our study with those reported by $\mathrm{He}$ and Yang (1990) from the Kuroshio (just downstream of our section) and adjacent waters. The numbers of copepod species found in each station range from 8 to 94 (mean 51) in He and Yang (1990) and from 21 to 64 (mean 45) in our study. The Shannon species diversity index and Simpson's evenness in our study, respectively varying from 1.3904 to 3.1315 (mean 2.5838 ) and 0.5015 to 0.8860 (mean 0.7759 ), are 
also smaller than those of He and Yang (1990): from 0.8898 to 5.6524 (mean 3.9529) and 0.2966 to 0.8780 (mean 0.7205). It should be cautioned, however, that $\mathrm{He}$ and Yang included all species in their calculation, while the present study only considered the selected species

The dendrogram of the species association depicts some relationships among the twenty most abundant species in our collection (Fig. 3). It links the widely distributed species (in the upper part of the dendrogram) and the species that at most rarely occur in the coastal water (the lower part of the dendrogram) to close clusters. The species (from Clausocalanus arcuicornis to Scolecithrix danae) that form the middle clusters of the dendrogram are, however, lacking of traits in the distribution pattern, except that they are mostly widely distributed in subtropical and tropical waters around the world.

The temperature-salinity curves for stations 1 and 3 are nearly straight, showing a linear $\mathrm{T}-\mathrm{S}$ relationship in the shallow coastal area. The low salinity and low temperature are due to freshwater runoff and cold coastal currents from the north. The higher temperature and salinity in the lower water of station 3 indicate a strong influence of the ECS. This influence is reflected in the dendrogram of station association where station 3 joins with station 7 in a cluster (Fig. 4). Station 20 is near the most westward part of the Kuroshio. The characteristic T-S curve of the KUR at station 20 confirms previous report of the westward location of the Kuroshio intrusion (Hwang and Tang, 1993). The upper part of the $\mathrm{T}-\mathrm{S}$ curve in station 20, however, leans toward that of stations 11 and 12, an indication of strong influence from the MIX. This influence is also demonstrated in the dendrogram of station association where stations 20 is linked with stations 11 and 12 (not 15) to form a cluster. This close similarity in $\mathrm{T}-\mathrm{S}$ curves between stations also illustrates the species composition. For instance, the composition of the species is highly similar in stations 3 and 7. There are more deepwater species belonging to the Scolecithricidae in station 20 than in other stations, probably brought up to the upper layer by the upwelled Kuroshio subsurface water. Most of these scolecithricids are known from the Kuroshio (Chen and Zhang, 1965). A similar distribution pattern is also found in ichthyoplankton in the intermediate waters of KUR-MIX (Chiu and
Lee, 1991) and some mesopelagic gonostomatid species become abundant in the vicinity of station 20 (Chen and Chiu, 1992).

\section{Acknowledgements}

The National Research Council of the Republic of China is thanked for a grant to support the KEEP-II research project and a research fellowship for $\mathrm{CtS}$ through TSC. The Canadian Museum of Nature awarded a sabbatical leave for $\mathrm{CtS}$ to participate in the KEEP-II project The captain and crew of the Ocean Research I helped us to collect the samples and other environmental data related to this study. We are grateful for the technical and logistic support given to us by Mr. J.B. Huang, Mr. W.B. Huang, Ms. K.Z. Chang, and Ms. C.C. Chen of the Economic Fish Laboratory, National Taiwan University. Dr. Y.S. Lin, then Chairman of the Zoology Department, NTU, and his staff are credited for providing $\mathrm{CtS}$ with working facilities. We are very grateful to two anonymous reviewers for their constructive comments on an earlier version of the manuscript.

\section{References}

Bradford, J.M., 1974. Euchaeta marina (Prestandrea) (Copepoda, Calanoida) and two closely related new species from the Pacific. Pac. Sci. 28, 159-169.

Chen, C.S., Chiu, T.S., 1992. Comparison of ichthyoplankton guild in the Kuroshio edge exchange area. Terrestr., Atmos. Oceanic Sci. 3, 335-346.

Chen, H.Y., Chen, Y.L.L., 1992. Quantity and quality of summer surface net zooplankton in the Kuroshio Current-induced upwelling northeast of Taiwan. Terrestr., Atmos. Oceanic Sci. 3, 321-334.

Chen, Q., 1992. Zooplankton of China Seas (1). Science Press, Beijing, 87 pp.

Chen, Q.C., Zhang, S.Z., 1965. The planktonic copepods of the Yellow Sea and the East China Sea, I. Calanoida (in Chinese, with English summary). Stud. Mar. Sin. 7, 20-131.

Chen, Q.C., Zhang, S.Z., Zhu, C.S., 1974. On planktonic copepods of the Yellow Sea and the East China Sea, II. Cyclopoida and Harpacticoida (in Chinese, with English summary). Stud. Mar. Sin. 9, 27-76.

Chen, Y.L.L., 1995. Phytoplankton composition and productivity in response to the upwelling of northeastern Taiwan. Proc. Natl. Sci. Counc., ROC 19B (1), 66-72. 
Chern, C.S., Wang, J., 1989. On the water masses at northern offshore area of Taiwan. Acta Oceanogr. Taiwan. 22, 14-32.

Chern, C.S., Wang, J., Wang, D.P., 1990. The exchange of Kuroshio and East China Sea shelf water. J. Geophys. Res. 95, 16017-16023.

Chiu, T.S., 1991. Variation of ichthyoplankton density across the Kuroshio edge exchange area with implication to the water masses. Terrestr., Atmos. Oceanic Sci. 2, 147-262.

Chiu, T.S., Hsyu, Y.H., 1994. Interannual variation of ichthyoplankton density and species composition in the waters off northeastern Taiwan. Mar. Biol. 119, 441-448.

Chiu, T.S., Lee, P.Y., 1991. Initial ichthyoplankton studies in the Kuroshio edge exchange area. Bull. Inst. Zool., Acad. Sin. 30, 261-272.

Frost, B.W., 1989. A taxonomy of the marine calanoid copepod genus Pseudocalanus. Can. J. Zool. 67, 525-551.

Grice, G.D., 1963. A revision of the genus Candacia (Copepoda: Calanoida) with an annotated list of the species and a key for their identification. Zool. Meded. 37, 171-193.

He, D., Yang, G., 1990. Distribution of the pelagic copepods in the Kuroshio upstream and adjacent waters in spring, 1986 (in Chinese, with English summary). In: Sun, X. (Ed.), Essay on the Investigation of Kuroshio. Ocean Press, Beijing, pp. 329334.

Hwang, S.J., Tang, T.Y., 1993. Distribution of CTD Observation, Distribution of Salinity Contour, Distribution of Density Contour. CTD Data Bank Data Report, Regional Instrument Cen- ter, R/V Ocean Researcher I, National Science Council, Taipei, 2, pp. 1-523.

Liu, K.K., Gong, G.C., Shyu, C.Z., Pai, S.C., Wei, C.L., Chao, S.Y., 1992. Response of Kuroshio upwelling to the onset of the northeast monsoon in the sea north of Taiwan: observations and a numerical simulation. J. Geophys. Res. 97, 1251112526.

Mori, T., 1937. The Pelagic Copepoda from the Neighbouring Waters of Japan. Soyo Company Inc., Tokyo, 150 pp., 80 pls.

Rholf, F.J., 1989. Numerical Taxonomy and Multivariate Analysis System (version 1.50). Exeter Publ. Ltd., New York.

Shiah, F.K., Gong, G.-C., Liu, K.K., 1995. A preliminary survey on primary productivity measured by the $14 \mathrm{C}$ assimilation method in the KEEP area. Acta Oceanogr. Taiwan. 34, 1-15.

Shih, C.-t., 1979. East-west diversity. In: van der Spoel, S., Pierrot-Bults, A.C. (Eds.), Zoogeography and Diversity of Plankton. Bunge Scientific Publishers, Utrecht, pp. 87-102.

Tan, T.H., 1967. On distribution of copepods in the surrounding waters of Taiwan. Report of the Institute of Fishery Biology of Ministry of Economic Affairs and National Taiwan University, 2(2), pp. 14-20.

Tseng, W.Y., 1972. On Copepoda of the family Candaciidae in the northeast sea-waters of Taiwan. In: Sugawara, K. (Ed.), The Kuroshio II. Proceedings of the Second Symposium on the Results of the Cooperative Study of the Kuroshio and Adjacent Regions, Tokyo, September 28-October 1, 1970. Saikon Publishing Comp. Ltd., Tokyo, pp. 245-259. 